\title{
10
}

\section{Health Aspects of Bioaerosols}

Harry Salem and Donald E. Gardner

\section{Introduction}

Bioaerosols have been defined as colloidal suspensions in air of liquid droplets or solid particles, containing, or having attached to them, one or more living organisms. These organisms include viruses, bacteria, fungi, protozoa, or algae. Bioaerosols may range in size from a single microorganism to large droplets containing many microorganisms. Microorganisms may also be attached to pollen grains, plant debris, skin flakes, and/or soil particles. Liquid droplets may change in size upon evaporation or condensation, which may or may not result in the loss of viability of the organism.

Bioaerosols are known to have a major impact on vegetation, livestock, ecology, the environment, and on the health of humans. The major human health aspect of bioaerosols is their use in the study of etiologic agents, control, prevention, and treatment in the spread of infection. Current concerns of airborne contagion include the environment, especially indoor air pollution in homes, schools, buildings, and hospitals. The incidence of airborne disease has been correlated with the extent of crowded conditions and poverty levels in our cities.

Most reviews of inhalation toxicology indicate that we live in a sea of chemicals. These chemicals can gain access to the body by means of inhalation and may affect the respiratory system directly, or by using this route as a portal of entry and then adversely affect some other part of the body (Salem, 1987). It is estimated that there are already almost 100,000 chemicals in commerce, with approximately 25,000 new entities synthesized yearly. Bacteria, viruses, and fungi have also been identified in ambient air. They can be transmitted to cause infection, but their survival in air is more limited than 
chemicals. In air, these microorganisms cannot grow or multiply because of the absence of nutrients, but they can be transmitted for long distances. Different microorganisms are found at various heights from the ground, and amounts and varieties of microbial populations in air are dependent on location and environmental conditions such as humidity and temperature, as well as the density and activity of humans (Al-Dagal and Fung, 1990). Viable microorganisms are known to occur up to altitudes of about 20 miles, and fungal spores have been found in air flights over the North Pole. The potential adverse effects of chemicals and biologicals in the environment on domestic animals, wildlife, fish, and plants must also be considered so that a balanced ecosystem is maintained. It must also be recognized that in spite of the sea of chemicals and biologicals we live in, life expectancy has increased over the last few decades, and the quality of life has improved.

This chapter will review the status of aerobiology in terms of respiratory infections with emphasis on airborne contagion, defense mechanisms, and the maintenance of homeostasis. In addition, where possible, a parallelism will be drawn between biologicals and chemicals.

Molecular biology and biotechnology have made genetic engineering and designer drugs a reality as well as blurring the demarcation between chemical and biological agents; the connecting link being agents of biological origin (i.e., poisonous products of microorganisms, animals, and plants) such as toxins. During World War II, various countries developed extensive biological arsenals and maintained them for years afterward. Much has been written on aerobiology and numerous conferences were held until 1969 when the United States under President Richard Nixon abandoned its research into biological weapons. Unfortunately, evidence points to just the opposite for the former Soviet Union. Since the 1970s, and until recently, they appear to have been pursuing an active program of research into biological agents for military use. The deaths caused by anthrax spread from a Soviet weapons laboratory in Sverdlovsk in 1979 is an example of this. The advances of genetic technology may have provided the Soviets with newer biological agents for which there are no vaccines or therapeutic regimens.

In the 1977 Senate Hearings, the Department of Defense acknowledged that in the 1950s, it had engaged in massive open-air tests in which it had released vast quantities of mildly pathogenic bacteria (Serratia marcescens and Bacillus subtilis) over San Francisco Bay and in the New York subway system. These tests appeared to have triggered disease outbreaks that caused at least one death (Yamamoto, 1989). Such studies were conducted to assess the survivability and dispersion patterns of the organisms. Over 250 years ago, smallpox and possibly typhus were reported to have been used as biological weapons during the French, British, and Indian wars in North America (Poupard et al., 1989). As recently as 1981, the Department of State declared that clouds of yellow rain (trichothecene toxins from fungi) were released over Laos, Kampuchen, and Afghanistan, causing illness and death. 
Some of the current concerns include the sources of bioaerosols, their particlesize distribution and dose responses, and airborne contagion.

\subsection{Sources of Bioaerosols}

Bioaerosols are aerosols containing living organisms such as viruses, bacteria, fungi, protozoa, or algae, as well as products of their metabolism or their decomposition such as toxins. Bioaerosols, in addition to causing infectious diseases, can act as sensitizing agents in susceptible hosts, similar to chemical aerosols. In addition, agents of biological origin such as toxins can also cause acute and chronic effects as do chemical aerosols.

Obligate parasitic microorganisms such as viruses, bacteria, and fungi require a living host for growth and reproduction. Although some of these organisms may survive on environmental surfaces for various durations of time, they only very rarely cause disease when they are reentrained into the air (Burge, 1990), except for organisms that have protective devices, such as spores.

Microorganisms, although frequently found in the air, do not multiply there. Outdoor air rarely contains pathogens due, in part, to the bactericidal effects of dessication and ozone and ultraviolet irradiation. Indoor air, however, may contain pathogenic organisms that are shed from the skin, hands, and respiratory tract of humans as well as from their clothing. Talking, coughing, and sneezing can produce respiratory droplets containing bacteria, and viruses can spread infection only to susceptible individuals in close proximity to the source. (Gallis, 1976).

The particulate form of matter containing bacterial or viral pathogens, or their products, determines and limits the atmospheric spread of infectious diseases. The size or settling velocity determines the duration of time that pathogens are in the air. This limits the probability of transfer between persons in the environment. Hatch and Gross (1964) have shown that for a $63 \%$ reduction in the concentration of particles by gravity settlement in a confined space $10 \mathrm{ft}$ high, requires less than 10 min for particles greater than $13 \mu \mathrm{m}$ and several hours for single bacterial particles of 2-3 $\mu \mathrm{m}$. The removal of particles from the air is also dependent on ventilation. It is apparent that the risk of direct respiratory exchange of infectious particles is from the small particles dispersed from the respiratory tracts of infected individuals and that the hazard from the inhalation of particles resuspended from dust deposits on the floor is limited by their relatively large size.

Microorganisms are dispersed into the air as liquid droplets varying in size from greater than $100 \mu \mathrm{m}$ to less than $10 \mu \mathrm{m}$. Salem and Aviado (1970) have reported that of the respiratory activities of sneezing, coughing, and talking, sneezing produces the highest proportion of the small droplets. Nearly all of the small droplets containing airborne bacteria have been reported to originate from 
the front of the mouth. Only a few originate from the nose (Duguid, 1945). The spread has been observed by high-speed stroboscopic light photography. The smaller droplets remain suspended in air, evaporate quickly, and leave droplet nuclei a few micrometers in diameter which may or may not contain microorganisms. The droplet nuclei settle very slowly and may remain suspended in air almost indefinitely, especially in a room with people where the air currents keep them suspended. This creates an environment with a high concentration of potentially infective particles. Larger particles are expelled up to a distance of $2 \mathrm{~m}$ and at a velocity of at least $152 \mathrm{ft} / \mathrm{s}$ (Gallis, 1976; Jennison, 1942). These large particles fall rapidly to the floor, where they dry and may attach to dust particles which could be resuspended by sweeping, dusting, movement such as walking, and wind.

As far back as 1934, Wells demonstrated that large particles evaporate rapidly and these residual particles which he called droplet nuclei were only a few micrometers in size. He also showed that even in an atmosphere of $90 \%$ relative humidity, droplets with diameters in the order of $80 \mu \mathrm{m}$ evaporate before settling to the floor from a height of $6 \mathrm{ft}$. These particles which may contain virulent pathogens are, thus, capable of remaining in atmospheric suspension over long periods of time during which they can be inhaled by susceptible individuals sharing the same confined atmosphere.

\subsection{Particle Size and Dose-Response}

The particle size of the bioaerosol determines the duration of its availability in the atmosphere, the distance it can travel, and the site of its ultimate deposition in the respiratory tract of the next host. Hatch (1961) has shown that for droplet nuclei $(2-3 \mu \mathrm{m})$, pulmonary deposition is higher than that for the upper respiratory tract, whereas for dust-borne bacteria and droplets, deposition is essentially limited to the nasopharyngeal area (see Fig. 10.1). Wells et al. (1948) suggested that to establish disease, the infectious particles must be deposited as virulent organisms at the critical site and that only droplet nuclei can contribute significantly to the atmospheric spread of diseases initiated by deposition of infectious particles in the lungs. This was demonstrated in their quantitative study of tuberculosis infection in rabbits. Using suspensions of tubercle bacilli as single organisms of $2-3 \mu \mathrm{m}$ and $13 \mu \mathrm{m}$, they found that the number of tubercles developing in the rabbits' lungs approximated the number of inhaled organisms of $2-3 \mu \mathrm{m}$, whereas only $6 \%$ of the $13-\mu \mathrm{m}$ bacilli reached the lungs to produce tubercles.

These studies not only confirmed their prediction that larger particles would not reach the depths of the lungs but also demonstrated the selectivity of tissue susceptibility. Tubercle bacilli implanted on the mucosa of the upper respiratory tract proved to be innocuous. Effective contact requires implantation on a particu- 


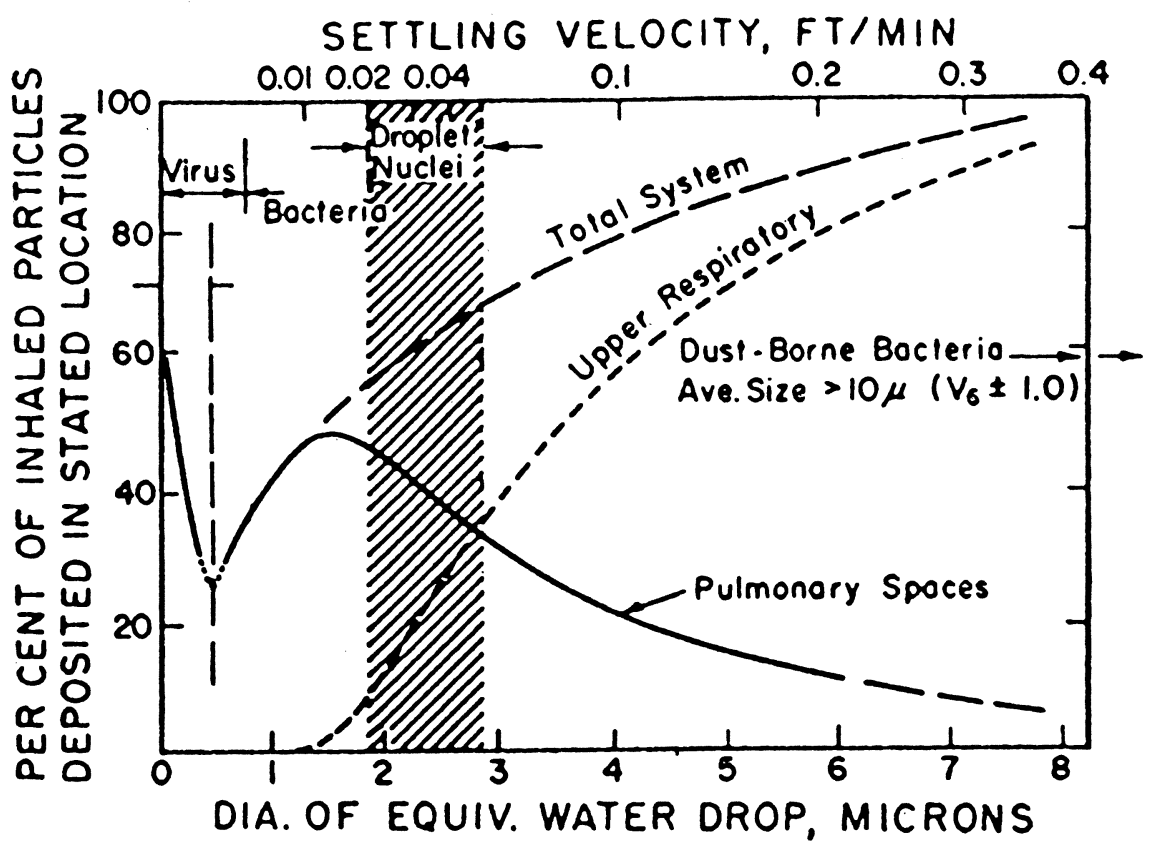

Figure 10.1. Total and regional deposition of inhaled particles in relation to aerodynamic particle size, showing relative positions of viral and bacterial particles, droplet nuclei, and dust-borne bacteria on the size-deposition curve [From Hatch (1961).]

lar part of the respiratory tract, or a part from which susceptible tissue can be reached. This is in contrast to chemical aerosols where deposition, also dependent on particle size, can cause damage and lethality at any region of the respiratory tract. Therefore, it was recommended that for toxicity testing in rodents, particle sizes between 1 and $4 \mu \mathrm{m}$ be used (Salem et al., 1992).

Studies by Druett et al. (1953) also found striking differences in the atmospheric concentration of anthrax spores of different sizes required to produce disease in $50 \%$ of the exposed animals. There was a 17 -fold increase in the concentration of particles larger than $12 \mu \mathrm{m}$ to produce disease than with anthrax spores smaller than $5 \mu \mathrm{m}$. The results were independent of the number of spores in a particle.

Goodlow and Leonard (1961) confirmed this finding with aerosol particles of Pasturella tularensis of different sizes. To produce 50\% mortality in guinea pigs and rhesus monkeys required 3 and 17 cells of $1 \mu \mathrm{m}$ particle size, 6500 and 240 cells of $7 \mu \mathrm{m}$ particle size, 20,000 and 540 cells of $12 \mu \mathrm{m}$ particle size; and 170,000 and 3000 cells of $22 \mu \mathrm{m}$ particle size, respectively.

Brucellosis, a zoonotic disease, can be transmitted from its animal reservoir to humans by the inhalation of infectious aerosols in addition to skin and conjunctival contact as well as ingestion. Aerosol transmission of brucellosis has been widely 
accepted as a potential biohazard in laboratories and its potential spread at abattoirs has been reviewed by Kaufmann et al. (1980).

In a cross-sectional epidemiological study associating air quality with swine health, Donham (1991) was able to demonstrate that bacterial concentration (respirable and total microorganisms) was highly correlated to pneumonia. Other air contaminants (dust, ammonia, and carbon dioxide) were also found to be correlated with swine health problems. On the basis of dose-response correlation to swine health or human health problems, the recommended maximal safe microbial concentration of total microbes was $1 \times 10^{5}$ colony forming units per meter square $(\mathrm{cfu})$.

\subsection{Airborne Contagion}

Wells (1955) originally described airborne contagion as the chain reaction indoors resulting from person-to-person transfer of droplet nuclei implicated in respiratory tract infection. At a Conference on Airborne Contagion sponsored in 1979 by the New York Academy of Sciences, the concept of airborne contagion was expanded to include aerosols from inanimate sources such as air conditioners, dental drills, fungal spores from soil, and insulating materials, as well as longrange outdoor transfer of microorganisms. Air is a vehicle for dissemination of microorganisms, whether dynamic contagion is involved with a geometric increase in cases or static infection arising from a single source and whether humans, animals or plants are implicated as hosts (Kundsin, 1980).

The trachea, bronchi, lungs, and sinuses are usually sterile. The nasopharynx is the natural habitat of the common pathogenic microorganisms that cause infections in the nose, throat, bronchi, and lungs. Humans are the primary hosts for these microorganisms. The reservoir from which infections are spread are patients and healthy carriers. Some people become nasal carriers for streptococci and staphylococci and discharge these organisms in large amounts into the air from their noses (Gallis, 1976). In any case, the microorganisms or chemicals must reach a susceptible and/or immunologically compromised individual to cause infection and/or adverse effects. Interaction of infectious microorganisms with other air pollutants can increase susceptibility of the individual or the severity of the effect (Gardner, 1988; Graham et al., 1987; Parker et al., 1989; Spengler and Sexton, 1983).

Many microorganisms can cause human disease when they are airborne in sufficient numbers. Many environmental and physiological factors play a significant role in the pathogenesis of infectious diseases. These factors are discussed in detail in later sections of this chapter. Bacteria and fungi can produce spores that are hardy and may persist in the environment for many years. Some can cause infection long after the initial contact, and others can cause hypersensitivity disease. Spores produced by fungi are easily transported through the air, and 
their concentrations in the air are subject to seasonal, diurnal, and geographic variations. The outdoors are abundant with fungal spores which freely penetrate indoors by many routes, including open windows and mechanical air intakes. In ventilated buildings, the indoor air concentrations are directly correlated with the outdoor concentrations. Additionally, many thousands of spores are present per gram of surface dust in most enclosed spaces (Spendlove and Fannin, 1983).

It has been shown by Kaminski et al. (1974) that many microorganisms are capable of producing volatile organic compounds (VOCs) which can be irritants or systemic toxins. Low levels of these compounds have been associated with moldy or mildewy odors. Burge (1987) has reported that microorganisms also produce a variety of higher-molecular-weight toxins.

Mannis et al. (1986) have reported that protozoa are unicellular, often motile organisms grown in indoor reservoirs and can cause severe infections as well as producing antigenic or toxic metabolites. These may contribute to hypersensitivity pneumonitis and humidifier fever (Edwards et al., 1976).

The emphasis on energy conservation will require the recirculation of air, whether heated or conditioned. Thus, less make up outdoor air from the outside will be required.

In addition, making buildings more air-tight will result in higher exposures to more recirculated air with an increased potential for exposure to more airborne microorganisms. Although there have been threshold limit values (TLVs) for chemicals published since 1971, there are no threshold levels for viable particles as of the latest TLVs published by the American Conference of Governmental Industrial Hygienists (ACGIH) for 1991-1992. Perhaps limits will be established for them so that they will be controlled along with temperature and humidity.

Examples of microorganisms causing respiratory infection or sensitization when inhaled are presented in Table 10.1.

\subsection{Biotechnology and Genetic Engineering}

Molecular biology research on the manipulation of the gene inaugurated genetic engineering. New strains of microbes and plants are possible through biotechnology and genetic engineering. In addition, vaccines can be produced from microbial and viral genes by these techniques. Biotechnology utilizes living organisms and their products for the industrial production of biologically active mammalian proteins such as insulin and the human growth factor. This technology also permits research on the functional organization of genetic information. Genetic engineering allows analysis of the gene and DNA sites that control genetic expression. The potential of this technology is limited only by the creativity and imagination of the human intellect.

The discipline of biotechnology emerged as a result of breakthroughs in recombinant DNA and hybridomas. Recombinant DNA technology is gene splicing or 
genetic engineering which involves inserting genetic material from one organism into another. Utilizing this technology it is hoped that many of the genetic misinstructions which lead to genetic disorders including hemophilia, spina bifida, Down's syndrome, cystic fibrosis, and diabetes can be erradicated.

Biotechnology has already led to the development of new pharmaceuticals, crop plants, livestock varieties, and other products. Genetic engineering uses recombinant DNA techniques to rearrange genes by removing, adding, or transfering them from one organism or location to another. Restriction enzymes are employed to cut out a gene sequence from one organism and insert it into the plasmid of another. The genes are usually implanted in microorganisms such as single-cell bacteria, yeast, or Chinese hamster ovary cells. The recipient organism then carries out the instructions of the inserted gene. Human insulin, for example, is manufactured by inserting the human gene into the bacteria Escherichia coli which multiply in fermentation tanks, producing the polypeptide hormone. Other pharmaceutical products which have been or are being developed through biotechnology are presented in Table 10.2 (Baum, 1987a).

In 1992, the U.S. Food and Drug Administration proposed to regulate products of genetic engineering, and not the process by which they are created. The proposed guidelines for regulating new varieties of foods suggest that the agencies charged with preserving public health do not need special rules to oversee genetically engineered organisms. Foods developed through genetic engineering including fruits, vegetables, and grains will be regulated within the framework of the Federal Food, Drug and Cosmetic Act. The level of oversight will be based on the characteristics of the food and its intended use rather than the method by which it was produced. It is expected that many of the gene-altered foods being introduced will not require premarket FDA approval, unless the process increases the concentration of naturally occurring toxicants in the plant, introduces an allergen not normally found in the plant, or alters the nutritional composition of the plant (Gershon, 1992).

Important therapeutic products to treat cancer and other diseases are being developed using monoclonal antibodies. Immunotherapy for cancer is based on the assumption that tumor cells possess immunogenic characteristics different from those of normal cells. Monoclonal antibodies have been developed that bind preferentially to tumor cells. Such antibodies after binding to tumor cells can activate host defense mechanisms against those cells. Immunotoxins on the other hand, utilize the antibody as a vehicle for a toxic agent that kills the tumor cells directly. Antibody conjugates have been made with chemotherapeutic agents such as methotrexate or with ribosomal inhibitor proteins such as ricin to prepare immunotoxins. Monoclonal antibodies are also being designed to bind to and neutralize endotoxins. Endotoxins are released by a broad spectrum of bacteria to cause septic shock which is characterized by a precipitous drop in blood pressure, blood clotting abnormalities, failure of major organ systems, and death.

Agricultural biotechnology products are also being developed with the potential 


\begin{tabular}{|c|c|c|c|}
\hline Disease & Causative Organism & $\begin{array}{l}\text { Primary } \\
\text { Reservoir }\end{array}$ & Reference \\
\hline \multicolumn{4}{|l|}{ Bacterial Disease } \\
\hline Pneumonia & Streptococci pneumoniae & Humans & Ketchum (1988) \\
\hline $\begin{array}{l}\text { Pneumonia, } \\
\text { nosocomial infection }\end{array}$ & Klebsiella pneumoniae & Humans & Ketchum (1988) \\
\hline Pneumonia & Haemophilius influenzae & Humans & Ketchum (1988) \\
\hline Walking pneumonia & $\begin{array}{l}\text { Mycoplasma } \\
\text { pneumoniae }\end{array}$ & Humans & Ketchum (1988) \\
\hline Q fever & Coxiella burnetii & Animals (sheep) & Ketchum (1988) \\
\hline $\begin{array}{l}\text { Ornithosis, psittacosis, } \\
\text { parrot fever }\end{array}$ & Chlamydia psittaci & $\begin{array}{l}\text { Birds (domestic and } \\
\text { wild) }\end{array}$ & Ketchum (1988) \\
\hline Brucellosis $^{\mathrm{a}}$ & Brucella melitensis & Animals & $\begin{array}{l}\text { Ketchum (1988); } \\
\text { Kaufmann et al. (1990) }\end{array}$ \\
\hline $\begin{array}{l}\text { Legionnaires' disease, } \\
\text { Pontiac fever }\end{array}$ & $\begin{array}{l}\text { Legionella pneumophila, } \\
\text { Legionella anisa }\end{array}$ & $\begin{array}{l}\text { Water (indoor and } \\
\text { outdoor) }\end{array}$ & $\begin{array}{l}\text { Fraser (1980); Mallison, } \\
\text { (1980); Breiman et al. } \\
\text { (1990); Fenstersheib et } \\
\text { al. (1990); O'Mahony } \\
\text { et al. (1990); Lee and } \\
\text { West (1991) }\end{array}$ \\
\hline Tuberculosis & $\begin{array}{l}\text { Mycobacterium } \\
\text { tuberculosis }\end{array}$ & Humans & Ketchum (1988) \\
\hline $\begin{array}{l}\text { Hypersensitivity } \\
\text { pneumonitis }\end{array}$ & Thermoactinomyces & $\begin{array}{l}\text { Heated water, soil, } \\
\text { compost, moldy } \\
\text { hay }\end{array}$ & Burge (1990) \\
\hline Diphtheria & $\begin{array}{l}\text { Corynebacterium } \\
\text { diphtheriae }\end{array}$ & Humans & Ketchum (1988) \\
\hline $\begin{array}{l}\text { Pertussis, whooping } \\
\text { cough }\end{array}$ & Bordetella pertussis & Humans & Ketchum (1988) \\
\hline Inhalation anthrax & Bacillus anthracis & Animals & $\begin{array}{l}\text { Brachman (1980); } \\
\text { Ketchum (1988); } \\
\text { Titball et al. (1991) }\end{array}$ \\
\hline $\begin{array}{l}\text { Bubonic plague }{ }^{\mathrm{a}} \text {, } \\
\text { pneumonic plague }\end{array}$ & Yersinia pestis & Animals & Ketchum (1988) \\
\hline Tularemia & Francisella tularensis & Animals & Ketchum (1988) \\
\hline \multicolumn{4}{|l|}{ Viral Disease } \\
\hline Influenza & $\begin{array}{l}\text { Influenza } A, B \text {, and } C \\
\text { viruses }\end{array}$ & Humans & Ketchum (1988) \\
\hline Croup & Parainfluenza viruses & Humans & Ketchum (1988) \\
\hline $\begin{array}{r}\text { Bronchiolitis, } \\
\text { pneumonia }\end{array}$ & $\begin{array}{l}\text { Respiratory syncytial } \\
\text { virus (RSV) }\end{array}$ & Humans & Ketchum (1988) \\
\hline Mumps $^{\mathrm{a}}$ & Mumps virus & Humans & Ketchum (1988) \\
\hline Measles & Rubella virus & Humans & Ketchum (1988) \\
\hline Common cold & $\begin{array}{l}\text { Rhinoviruses, } \\
\text { coronaviruses } \\
\text { parainfluenza viruses }\end{array}$ & Humans & $\begin{array}{l}\text { Gwaltney (1980); } \\
\text { Ketchum (1988) }\end{array}$ \\
\hline
\end{tabular}


Table 10.1. (Continued).

\begin{tabular}{|c|c|c|c|}
\hline Disease & Causative Organism & $\begin{array}{l}\text { Primary } \\
\text { Reservoir }\end{array}$ & Reference \\
\hline \multicolumn{4}{|l|}{ Viral Disease } \\
\hline $\begin{array}{l}\text { Chicken pox }{ }^{\mathrm{a}} \\
\text { (varicella) Zoster } \\
\text { (shingles) }\end{array}$ & Varicella-Zoster virus & Humans & $\begin{array}{l}\text { Lange (1976); Ketchum } \\
\text { (1988) }\end{array}$ \\
\hline Smallpox ${ }^{\mathrm{a}}$ & Variola virus & Humans & Joklik (1976) \\
\hline \multicolumn{4}{|l|}{ Fungal Disease } \\
\hline Asthma, rhinitis & Alternaria & $\begin{array}{l}\text { Outdoor air, dead } \\
\text { plants }\end{array}$ & Burge (1990) \\
\hline Asthma, rhinitis & Cladosporium & $\begin{array}{l}\text { Outdoor air, dead } \\
\text { plants }\end{array}$ & Burge (1990) \\
\hline Asthma, rhinits & Penicillium & $\begin{array}{l}\text { Indoor/outdoor } \\
\text { damp organic } \\
\text { material }\end{array}$ & Burge (1990) \\
\hline $\begin{array}{l}\text { Pulmonary } \\
\text { aspergillosis }\end{array}$ & Aspergillus & Soil, compost & Herman (1980) \\
\hline Coccidioidomycosis & Coccidioides immitis & Soil of arid regions & Ketchum (1988) \\
\hline Histoplasmosis & Histoplasma capsulatum & $\begin{array}{l}\text { Animals, soil, } \\
\text { keratonaceous } \\
\text { material (feathers) } \\
\text { in soil }\end{array}$ & Conant (1976) \\
\hline \multicolumn{4}{|l|}{ Protozoan Disease } \\
\hline $\begin{array}{c}\text { Hypersensitivity } \\
\text { pneumonitis }\end{array}$ & Protozoa & Water reservoirs & Burge (1990) \\
\hline \multicolumn{4}{|l|}{ Algal Disease } \\
\hline Asthma, rhinitis & Alga & $\begin{array}{l}\text { Lighted water } \\
\text { reservoirs }\end{array}$ & Burge (1990) \\
\hline
\end{tabular}

${ }^{a}$ Diseases transmitted via respiratory tract, but signs of infection are seen elsewhere in the body.

to revolutionize the practice of agriculture. These products range from animal vaccines to microbial pesticides to herbicide resistant plants as well as transgenic "pharming" (Baum, 1987b; Glanz, 1992; Powledge, 1992). The technology for producing vaccines and therapy for diseases of farm animals and pets and for producing proteins such as bovine somatotropin (BST) is similar to the technology used in developing corresponding products for humans. Porcine somatotropin is also being developed. Consensus interferon was designed to have optimum characteristics for use in preventing bovine respiratory disease in cattle. A vaccine against feline leukemia, a leading cause of death in cats, was developed based on agricultural biotechnology. The major impediment for the interactions among microorganisms and the plants they colonize or infect has been the fear of releasing such genetically engineered microbes into the environment. Although our knowledge of plant biochemistry is considerably more limited than mammalian biochemistry, progress has been made in model systems such as petunia, 
Table 10.2. Genetically-Engineered pharmaceutical products

\begin{tabular}{|c|c|c|}
\hline Biotechnology Product & Type & Use \\
\hline Atrial natriuretic factor (ANF) & Peptide hormone & Reduce blood pressure \\
\hline Erythropoietin (EPO) & Peptide hormone & $\begin{array}{l}\text { Stimulates red blood cell production } \\
\text { to treat anemia associated with } \\
\text { dialysis }\end{array}$ \\
\hline Factor VIII & $\begin{array}{l}\text { Protein in blood clot } \\
\text { cascade reaction } \\
\text { (Protease) }\end{array}$ & Hemophelia \\
\hline $\begin{array}{l}\text { Tissue-type Plasminogen } \\
\text { Activator (TPA) }\end{array}$ & $\begin{array}{l}\text { Protein enzyme } \\
\text { (Protease) }\end{array}$ & Dissolves clots \\
\hline Superoxide dismutase (SOD) & $\begin{array}{l}\text { Protein enzyme } \\
\text { (Protease) }\end{array}$ & $\begin{array}{l}\text { Scavenges Superoxide radicals } \\
\text { With TPA to treat heart attacks and } \\
\text { transplant patients }\end{array}$ \\
\hline Epidermal growth factor (EGF) & Protein enzyme & $\begin{array}{l}\text { Epidermal cell proliferation in burn } \\
\text { and wound healing } \\
\text { Cataract surgery } \\
\text { Opthalmic conditions }\end{array}$ \\
\hline Fibroblast growth factor (FGR) & Protein & $\begin{array}{l}\text { Angiogenesis or growth of blood } \\
\text { vessels } \\
\text { Treat burns and wounds } \\
\text { Assists vascularizations of skin } \\
\text { grafts }\end{array}$ \\
\hline Human growth hormone $(\mathrm{HGH})$ & Protein & Pituitary dwarfism \\
\hline Interleukin-2 (IL-2) & Lymphokine & $\begin{array}{l}\text { Immune system } \\
\text { Cancer }\end{array}$ \\
\hline Interleukin-3 (IL-3) & Lymphokine & $\begin{array}{l}\text { Blood cell growth factor } \\
\text { Bone marrow transplants }\end{array}$ \\
\hline Tumor necrosis factor (TNF) & Lymphokine & $\begin{array}{l}\text { Cancer } \\
\text { Used with IL-2 and Interferon }\end{array}$ \\
\hline $\begin{array}{l}\text { Granulocyte colony-stimulating } \\
\text { factor (G-CSF) }\end{array}$ & Protein & $\begin{array}{l}\text { Leukemia } \\
\text { Cancer }\end{array}$ \\
\hline $\begin{array}{l}\text { Granulocyte-monocyte colony- } \\
\text { stimulating factor (GM-CSF) }\end{array}$ & Protein & Immune deficiency \\
\hline $\begin{array}{l}\text { Macrophage colony-stimulating } \\
\text { factor (M-CSF) }\end{array}$ & Protein & Infectious diseases \\
\hline
\end{tabular}

tobacco, and tomato species. The element unique to agricultural biotechnology is that regulatory approval is required for field tests of genetically engineered microbes and plants. Plants, to be agriculturally useful, must grow in a field and microbial pesticides have to be applied to those plants. Tobacco plants have been engineered to be resistant to crown gall disease and to manufacture medicine and proteins that would be too expensive to make by other means. Tobacoo leaves are infected with a genetically altered virus which prompts the leaves to make proteins on request. Genes are inserted to tell the virus how to make hemoglobin or other desired protein. An experimental AIDS drug, Compound $\mathrm{Q}$, has been extracted from engineered ground-up tobacco leaves. Hybrid corn 
is being developed to be herbicide-resistant, and Pseudomonas fluorescens was engineered to protect plants from frost damage. Products are also being created that possess specific desired traits in a fruit or seed. Bovine somatotropin (BST), a recombinant DNA version of growth hormone produced in the pituitary glands of cows, when administered to mature cows increases their milk production from 10 to $25 \%$ with only $6 \%$ more feed. It has no effect on humans or other primates. The BST gene is expressed in the bacteria Escherichia coli, which is how BST is produced. The bacteria Pseudomonas fluorescens has been engineered as an insecticide to protect the roots of corn plants from a pest called black cutworm.

Ways to utilize toxins produced by the bacteria Bacillus thuringiensis $(\mathrm{Bt})$ are being studied. The toxins interfere with insect digestive processes but are nontoxic to mammals, birds, fish, and other wildlife. The Bt toxins are rapidly biodegraded. $P$. fluorescens colonize the surfaces of a wide range of plants. A gene that encodes a B6 toxin has been transferred into a strain system that colonizes the roots of cornplants. An elegant marker system has been developed that allows genetically modified microorganisms in the environment to be followed. The technique can detect as few as one recombinant microbe in a gram of field soil. The system involves inserting $E$. coli genes (lac Z, lac Y) into $P$. fluorescens which gives it the ability to grow on lactose, a property no other $P$. fluorescens has. Progress is being made on inserting Bt toxin genes in plant tissues so that when insects or caterpillars eat the plant leaves or roots, they ingest the toxin and die. Bt toxin is expressed in tomato plants which become resistant to attacks by pests such as tomato hookworms and fruitworms. Bt toxins are toxic to caterpillars, beetles, and weevils. Some strains of $P$. fluorescens inhibit the growth of soil-borne fungi that either kill crop plants or destroy sufficient root mass to limit the plants growth significantly. These bacteria produce a hydrolytic enzyme chitinase which breaks down chitin, a common fungal cell-wall material. The genes that encode chitinase can be transferred to strains of $P$. fluorescens that colonize a specific crop's root system. Ice-minus $P$. fluorescens and $P$. syringae protect crops from frost damage. Tobacco and tomato plants are being engineered to be herbicide resistant. The gene that encodes the polygalacturonase enzyme which causes fruit to soften has been isolated from tomatoes. Reinserting this gene into tomatoes in a reverse or "antisense" orientation blocks most of the enzymes production and thus prolongs the life of the tomatoes.

Rapeseed, a plant related to mustard, is a very efficient oil producer. Efforts in Canada have resulted in a strain Canola which produces an edible oil. Rapeseed has also been engineered to produce high-value specialty oils that the plant does not normally produce.

Genetic engineers have also created "pharm" animals that produce therapeutically important proteins in bulk. Genetic manipulation has shown the feasibility of producing therapeutic proteins in the milk and blood of genetically altered cows, sheep, goats, pigs, and mice. TPA, Tissue Plasminogen Activator, an anti-blood-clotting agent used to treat heart attack victims is manufactured in 
bioreactor vats of recombinant bacteria and costs thousands of dollars a gram. Current research has produced transgenic goats which can produce as much as $3 \mathrm{~g} / \mathrm{L}$ of TPA in their milk. A single optimally producing goat could make as much therapeutic protein as a $1000-\mathrm{L}$ bioreactor so that TPA is available to more patients at much lower cost. A hydrophobic membrane protein was produced in the milk of transgenic mice. This protein which is a potential therapy for cystic fibrosis is difficult to make by other techniques. Lactoferrin, an antibacterial protein which is also difficult to make, can be produced in significant quantities in the milk from transgenic bull calf female offspring. Bovine systems could be a most plentiful source for lactoferrin and other proteins. Lactoferrin can be used to treat immune-suppressed patients and as a component of infant formula. Transgenic pigs have been developed that produce human hemoglobin in their blood for use in transfusions. Transgenic sheep were developed whose eggs were implanted with the gene for alpha-1-trypsin, a glycoprotein used to treat lifethreatening emphysema. These transgenic animals appear to be normal except for their drug-producing capabilities. Transgenics should be considered as an extension of traditional breeding practices, that is, a very sophisticated way of breeding for some desired trait. After the first transgenic animal is made, it is bred to produce more of the same. Products developed utilizing transgenic animal technology are efficacious and safe. Xenograph research is in progress to grow quasi-human organs in pigs for human transplant.

Many transgenic mice have been created not for producing pharmaceuticals, but to be genetically susceptible to certain human ailments so that drug treatment can be tested on them.

The revolution in vaccine development, fueled by progress in genetic engineering and immunology, offers hope in combating pathological disorders and even possibly AIDS. Previously, vaccines were developed empirically, mutating or killing disease-causing organisms and then testing to see if the preparation made from them were effective. At least two human vaccines were created using the new genetic engineering approach, both for hepatitis $\mathrm{B}$, and both on the market. The tools being used in the new approaches are also improving the understanding of the biology of infection and the immune response. Today, the new way to develop vaccines is with genetic-engineering tools. Genes from infectious pathogens that contain instructions for specific antigens can be isolated and inserted into a harmless bacteria or virus, which then produce the antigen. To the immune system, the harmless bacteria or virus appears to be the real pathogen, and the immune cells learn how to attack the pathogen without exposure to it. Before designing vaccines this way, investigators must understand the biology of each pathogen. Viruses and bacteria have many ways of invading the human body and its cells and, therefore, have evolved various mechanisms to evade the host defenses. The immune system displays an extraordinary array of cells during infection. These include macrophages which engulf and break down the invaders. B-lymphocytes which make antibodies that bind and kill bacteria 
and viruses before they infect cells. Cytotoxic T-lymphocytes kill infected cells in an attempt to prevent the spread of the pathogens, whereas helper-T-lymphocytes send signals to other immune system cells (Aldovini and Young, 1992).

Critics of biotechnologically derived food and drugs ignore the fact that selective breeding has produced desirable products in the cattle and horse industries, whereas agriculture has depended both on natural selection and selective breeding. With the use of biotechnology, desired genes can be inserted into bacteria, plants and animals to produce the desired end product quicker and more efficiently. Many viruses and bacteria have mutated and produced many drug-resistant strains. This emerging threat is caused by these microbes as they develop new pathways, new proteins, and new strategies for survival. Bacteria, even of different species, can exchange genetic material, including the gene for drug resistance, and that resistance can be transfered to other bacteria as well.

\subsubsection{Inhalation of Bioaerosols}

Both the site of deposition and the total dose of an airborne infectious agent delivered to the respiratory tract can be significantly affected by the uniqueness of the pulmonary anatomy; the route of breathing (nose versus oral-nasal); the depth and rate of airflow; and the physical properties which governs particle transport and deposition. Having a knowledge of these various factors can significantly improve our ability to (1) understand the pathogenesis of the infectious disease process; (2) extrapolate laboratory animal studies to humans; (3) predict and assess health risk associated with airborne pathogens; and (4) provide guidance in identifying a most effective mode of treatment for respiratory infections.

\subsubsection{Anatomical and Physiological Factors in Respiratory Deposition of Infectious Organisms}

The respiratory system can be conveniently divided into three major compartments or regions (Fig. 10.2). Each of these regions have unique anatomical features that can influence the fate, deposition, transport, and clearance pattern of entry of airborne microorganisms. It is not appropriate to go into great detail regarding the anatomic structure of the respiratory system in this chapter, but there are several excellent reviews devoted to this topic (Gardner et al., 1988; Crystal et al., 1991; McClellan et al., 1989; Miller et al., 1989). It is evident that the anatomical structure and the physical dimensions of the respiratory system are important factors that must be considered in understanding the deposition and fate of inhaled organisms. This brief review will provide a basic understanding of the anatomical and physiological factors associated with the inhalation of bioaerosols.

The upper respiratory portion (nasal pharyngeal region) consists of the area extending from the nares down to the epiglottis and larynx at the entrance to the 


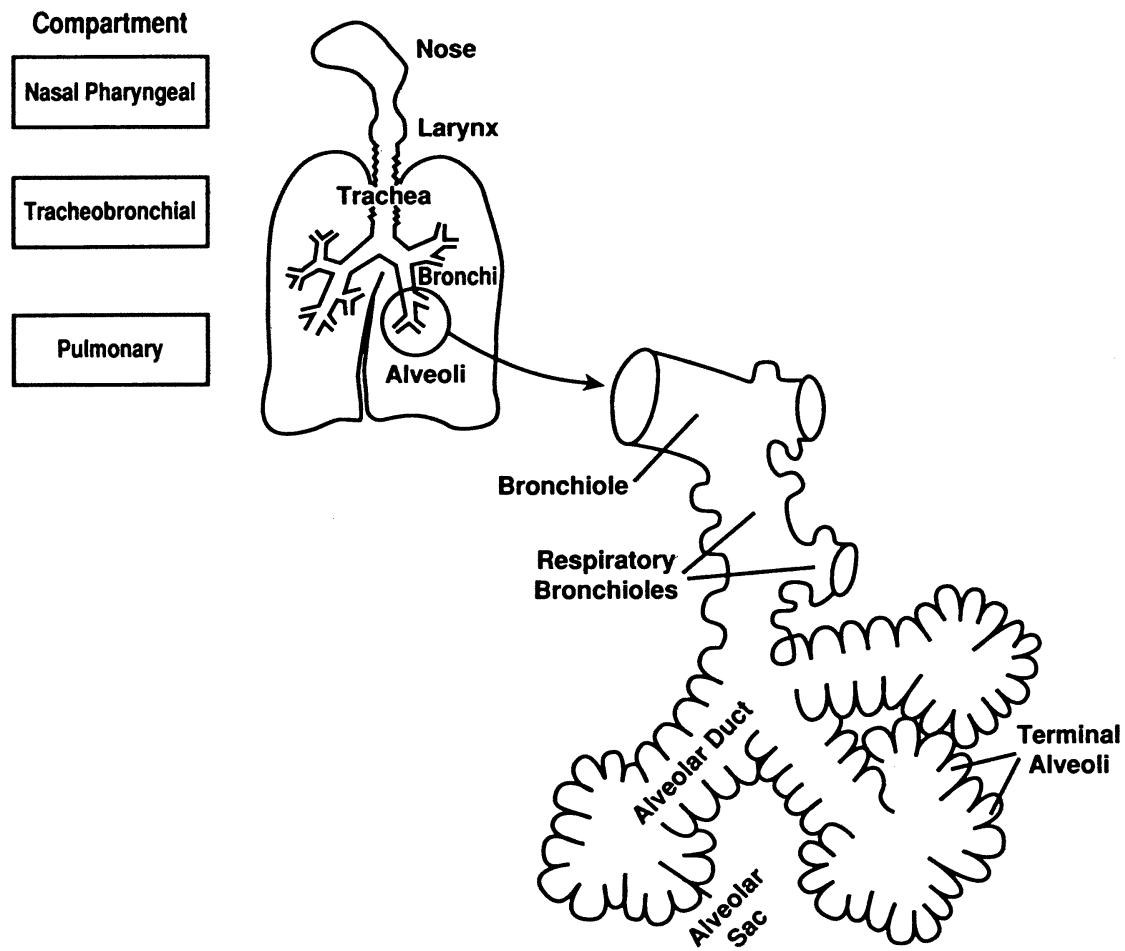

Figure 10.2. Major compartments of the respiratory system.

trachea. The mouth is included in this region and is important during mouth breathing.

This region has a complicated morphology consisting of the turbinates, epiglottis, glottis, pharynx, and larynx. The complicated shape of the nasal passages is not solely related to the role of the nose as an olfactory organ, but it also plays a major physiological function in the modification of the inspired air prior to its access to the lungs. Upon inspiration, the air enters the nose through the anterior nares passing into the airway passages where it is ultimately carried to the pharynx. These airway passages are lined with small hairs and ciliated mucous membranes which is rich with goblet and mucous-secreting cells. The high surface-to-volume ratio facilitates humidification and warming of the incoming air. In this region, the largest inhaled particles are removed by impaction and filtration. This uniqueness of the anatomical structure of this region plays a significant role in removing potentially harmful substances present in inhaled air from being deposited deeper in the respiratory system.

The tracheobronchial (TB) region consists of the conducting airways beginning at the trachea and extending down to the terminal bronchioles. The TB region 
functions to deliver inspired air to the deeper portions of the lung. The dimensions and number of branching airways varies from species to species, making definitive extrapolation of animal studies to man difficult. The trachea is an elastic tube supported by 16-20 cartilagineous rings that circle about three-fourths of its circumference and is the first and largest of a series of branching airways. The left and right lung are entered by two major bronchi that branches off the trachea into five separate lobes. In man, there are five lobes. The left lung consists of an upper and lower lobe, whereas the right lung has an upper, middle, and lower lobe. This may differ in laboratory animals, for example, although the rat also has five lobes, they have only a single lobe on the left and four on the right. The conducting airways in each lobe consists of up to 18-20 dichotomous branches from the bronchi to the terminal bronchiole. Beyond the terminal bronchi, the airways become very thin-walled and are referred to as respiratory bronchiole which have numerous small air sacs (alveoli) protruding from its walls.

Although the pulmonary region primarily functions in gas exchange, it also functions in pulmonary clearance and immunological defense. This region begins with the partially alveolated respiratory bronchioles.

The epithelium of the respiratory bronchioles is nonciliated. Each respiratory bronchiole divides into alveolar ducts. These ducts are actually bronchioles where almost their entire wall has been completely alveolated. These ducts lead ultimately into the alveolar sacs. The total number of ducts and sacs has been estimated to be $7 \times 10^{6}$ and $8.4 \times 10^{6}$, respectively (Gardner et al., 1988). The alveoli, which are evaginations of the alveolar sacs, are thin-walled, surrounded by a meshwork of blood capillaries. In the alveolus, the atmosphere and the blood are brought into an intimate contact where an equilibration between $\mathrm{O}_{2}$ and $\mathrm{CO}_{2}$ can take place. The surface of the alveoli is made up of primarily two types of cells. The Type- 1 cells are very thin and covers the greatest surface area. Type- 2 cells are larger, contain numerous microvilli, and produce and secrete a surface-lining fluid (surfactant) that functions in reducing surface tension which reduces the tendency for alveoli to collapse. The total respiratory surface of the lung has been estimated to be $50 \mathrm{~m}^{2}$ during expiration and as much as $100 \mathrm{~m}^{2}$ during the deepest inspiration.

\subsubsection{Dosimetry Factors for Inhaled Microorganisms}

The goals of experimental inhalation studies of bioaerosols in animal models are to be able to estimate infectivity in man and to be able to define the mechanisms of the pathogenesis of the airborne disease. Animal studies can provide a scientifically sound approach to providing cause-effect data under well-controlled and defined conditions with virtually unlimited exposure condition.

Aerosolization of viable organisms can be a serious threat to the microbes and, once launched into the air, the viability of the test organism and the actual 
number of airborne organisms reaching the respiratory tract may be greatly reduced. In bioaerosol studies, it is important to distinguish between the concentration generated and the dose. Posology is the study of dose and dosage. Although the term dose and dosage are usually used interchangeably, dose is total amount of a test article administered, whereas dosage is a relative amount. A dose of $10 \mathrm{mg}$, for example, means that this is the amount of material administered whether it is to a mouse, rat, dog, or human. Dosage, on the other hand, is the amount of material administered relative to body weight, body surface, and/or time $\left(\mathrm{mg} \mathrm{kg}^{-1}, \mathrm{mg} \mathrm{m}^{-2}\right)$. Inhalation dosage can be expressed as concentration or concentration and duration (i.e., $\mathrm{LC}_{50}$ as $\mathrm{mg} \mathrm{L}^{-1}, \mathrm{mg} \mathrm{m}^{-3}$, ppm, ppb, or $\mathrm{LCt}_{50}$ as $\mathrm{mg}-\mathrm{min} \mathrm{m}^{-3}$. Concentration or dosage in inhalation studies is the amount of material per unit volume, that is, the amount of a substance in the air or in the test medium. Dose refers to the total amount of the microorganism that is actually inhaled, delivered, and deposited to the tissue.

Developing a quantitative understanding of the relationship among exposure concentration, dose delivered to the tissue, and a specific pulmonary response is a basic fundamental goal of inhalation scientists. To achieve these goals requires information on deposition and the ultimate fate of the microorganism once deposited in the tissue. The term deposition refers specifically to the amount of inhaled airborne agent in the inhaled air that are deposited in regions of the respiratory tract. The fate of the organism can be expressed in terms of clearance, which refers to the subsequent translocation of and removal of deposited substances from the respiratory tract, and retention, which refers to the temporal pattern of residual substance that stay in the respiratory tract and are not cleared.

The infective dose for microbial aerosols has been shown in animals to be greatly influenced by particle size which, in turn, controls the site of deposition. Particle size is also critical where one part of the respiratory system is more susceptible to the inhaled organism than another. Airborne microbes may include particles varying in size from a single virus unit which could be as small as 0.1 $\mu \mathrm{m}$ in diameter to the largest fungal spores and pollens reaching sizes of 50 $100 \mu \mathrm{m}$.

There are a number of generic factors that can significantly influence the deposition of particles. Ventilation is important because (1) the physics of airflow is important to deposition mechanisms and (2) the rate and depth of breathing influence the volume of air and, hence, the mass of infectious agent entering the respiratory tract and the total surface area over which deposition can occur. Another important element is the route of breathing (oral, nasal, or oronasal). This influences filtering efficiency of inhaled materials and, thus, impacts the dose delivered to the lower respiratory tract.

Although most adults are nasal breathers at rest, they may resort to chronic or periodic mouth breathing under certain conditions such as exercise, nasal obstruction, or in the presence of chemical irritants. As respiratory demands increase, the proportion of air entering via the mouth also increases. Such action 
can significantly alter the pattern of deposition and, thus, the response to the inhaled substance. For instance, nearly $100 \%$ of particles having an aerodynamic size of about $10 \mu \mathrm{m}$ or larger are deposited in the nasopharyngeal region during nasal breathing. This compares to only about $65 \%$ deposition of such particles under conditions of oronasal breathing. There is also increased penetration of larger particles deeper into the respiratory tract with oronasal breathing. Although nasal breathing offers an effective means of protecting sensitive lower respiratory tract tissues from airborne particles, it should be remembered that rodents cannot breathe through their mouth, a factor that must be taken into consideration when extrapolating such animal data to man. Also, there exists a great difference in the complexity of the nasal passages resulting in differences in nasal airflow patterns between man and the laboratory animal which, in turn, may account for species-specific lesion distribution following inhalation exposure to certain substances. Although some of these morphological factors may be useful in protecting the deeper regions of the respiratory tract, it also makes the nose more vulnerable to the effects of particles, soluble gases, and vapors.

Chemical agents can alter physiological responses during exercise by causing pulmonary function changes (e.g., increased airway resistance through constriction) which tend to decrease the volume of air penetrating to the alveoli and can result in a shift to rapid, shallow breathing. Exercise has been shown to have a pronounced effect on pulmonary tissue uptake of gaseous pollutants but to have little effect on TB tissue. The deposition, clearance, and retention of inhaled particles has been extensively reviewed (National Research Council, 1991; Bates et al., 1989; Gardner et al., 1988).

For particles, the overriding factors influencing regional respiratory tract deposition are those based on aerodynamic properties, which, in turn, depend on a variety of physical properties. Particles of the same physical size do not necessarily behave the same aerodynamically. For example, a denser particle will tend to fall faster than a less dense particle of the same size. Therefore, the size of airborne particles is expressed in terms of their "aerodynamic diameter" which is the diameter equivalent to that of a theoretical spherical particle with a density of 1 that has the same terminal settling velocity (i.e., behaves aerodynamically in the same way) as the particle in question. Using such an adjustment permits a more valid comparison among particles of different physical sizes. These differences between actual and aerodynamic sizes are important in predicting respiratory deposition of inhaled particles.

After an infectious agent has entered the airways, it must first be deposited in a significant dose onto susceptible tissue to produce an effect. Figure 10.3 illustrates the five mechanisms by which particle deposition can occur: impaction, sedimentation, Brownian diffusion, interception, and electrostatic precipitation. Electrostatic attraction of particles to the walls of respiratory airways is a minor mechanism and is not important for the inhalation deposition of most environmental contaminants. Interception is more important for fiber deposition. 


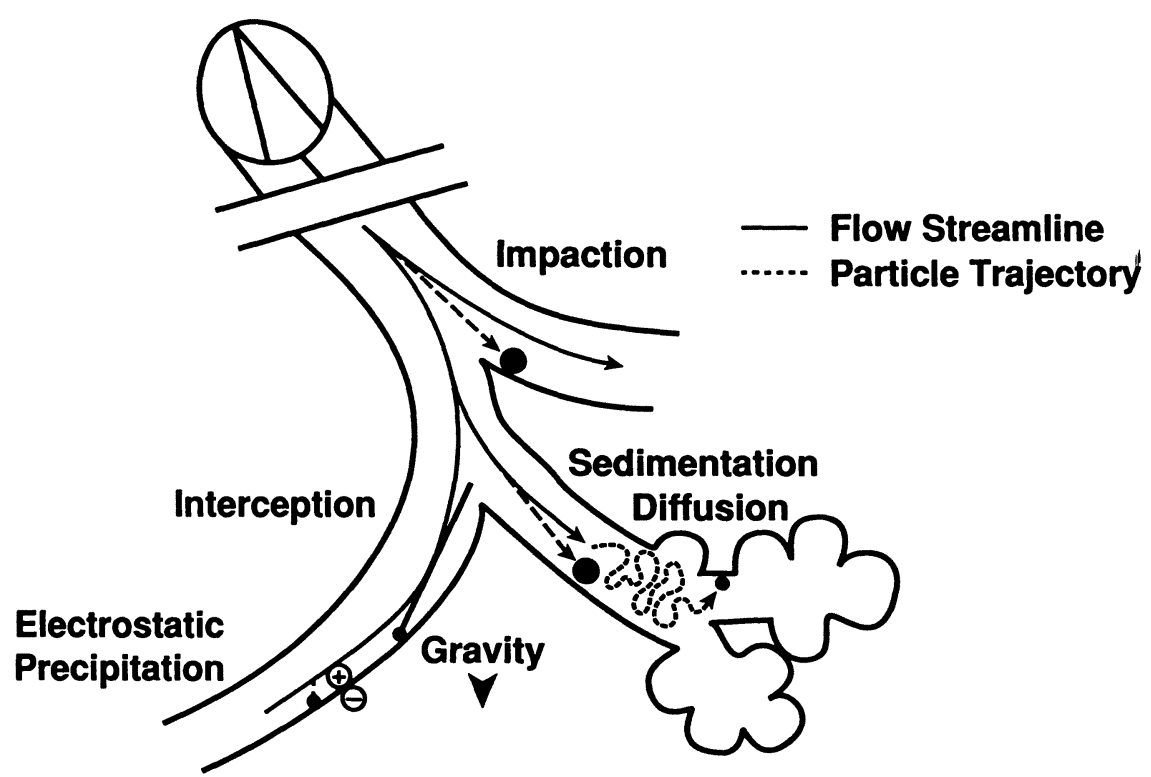

Figure 10.3. Mechanisms of particle deposition in the respiratory system.

Larger particles are removed from the inhaled air by the mechanism of impaction at the various bifurcations. Impaction onto an airway surface occurs when a particle's momentum prevents it from changing course in an area where there is a rapid change in the direction of the airflow. It is the main mechanism for the deposition of particles having an aerodynamic size of $\geq 2.0 \mu \mathrm{m}$. The largest sized particles are deposited in the anterior regions of the nose and are then most effectively cleared by mechanical means, including sneezing, coughing, and nose blowing. Deposited microbes may also be cleared from the upper airways by an effective mucociliary system which can transport the deposited particle from the airways to the throat, where it may be swallowed or expectorated.

The probability of impaction increases with increased air velocity, rate of breathing, particle size, and density. Sedimentation is deposition due to gravity and is important for particles with an aerodynamic size of $\geq 0.5 \mu \mathrm{m}$ in medium and small airways where the air velocity is relatively low. In this case, the particles will fall out of the airstream at a constant rate when the gravitational forces on the airborne particle is balanced by the total force due to air buoyancy and air resistance. The smallest particles $(\geq 0.5 \mu \mathrm{m})$ may be deposited onto the airway walls due to their bombardment by surrounding air molecules. Brownian diffusion is a major mechanism for deposition in airways where the airflow is low, such as found in the alveoli and bronchiole. Figure 10.1 depicts the regional deposition of inhaled aerosols as a function of aerodynamic diameter. 


\subsubsection{Infection}

The process of infection has been defined as an interaction of a host, a microorganism, and the environment. In the natural environment, healthy beings exist in an equilibrium with numerous potentially pathogenic microbes. Infection has been considered as a normal state of life and the process of disease merely as a disturbance of this equilibrium between the host and the parasite. In recent years, it has been shown that the environment may also play a major role in this process (Gardner, 1988; Graham et al., 1987; Parker et al., 1989; Coffin and Gardner, 1972).

Once deposited in the lung, the invading microorganism must be able to grow and multiply to produce disease. This is accomplished by increasing in number in a local lesion or by spreading systemically throughout the host. The success of the microbe depends on (1) the specific properties of the invading organism to produce disease and (2) the manner in which the infected host responses to the microbial invasion.

The pathogenicity or virulence of a infectious organism depends on its ability to grow and multiply in susceptible tissue. This requires an inherent biochemical ability to grow and to obtain the necessary nutrients within the respiratory tract and an ability to combat the pulmonary defense mechanisms that is present in the respiratory tract, which functions in clearing or killing the invading microbes. These include various humoral and cellular defense mechanisms of the host.

When clinically manifested injury to the host becomes evident, an overt infectious disease has occurred. At the other extreme, when the organism is deposited in the host and proliferates, at least enough to maintain its original numbers, but there is no evidence of inciting any adverse lost reaction, then colonization takes place. Between colonization and overt infections lies covert or subclinical infection.

In general, pathogenic microorganisms express their disease producing properties through two kinds of mechanisms: (1) the invasion and destruction of the host tissue and (2) the production of toxins. Table 10.3 lists examples of toxigenic pathogens. This can occur at the site of invasion or distally if metastatic infection occurs via bacteremia spread. Although many organisms cause disease by both invasion and toxin production, other are pathogenic primarily due to their invasive properties, for example, pneumococci aureus. Extracellular pathogens, (e.g., Streptococcus pyogenes, Staphylococcus aureus, and Diplococcus pneumoniae) are capable of producing disease only as long as they remain outside of defense (phagocytic) cells, whereas intracellular pathogens (e.g., Brucella abortus, Salmonella typhosa) can survive and multiply within these phagocytic cells and may actually destroy them.

The degree of virulence of an organism may also be due to certain enzymes and other metabolic substances that are produced by the organisms. These biological 
Table 10.3. Principal bacterial toxins.

\begin{tabular}{lll}
\hline Toxigenic Species & \multicolumn{1}{c}{ Toxin } & \multicolumn{1}{c}{ Disease } \\
\hline Clostridium botulinum & Type-specific neurotoxins & Botulism (neurotoxin, paralytic) \\
Clostridium perfringens & $\alpha$-Toxins and others & Gas gangrene \\
Clostridium tetani & Tetanospasmin; tetanolysin & Tetanus \\
Corynebacterium diphtherine & Diphtheria toxin & Diphtheria (modifies enzymes) \\
Staphylococcus aureus & $\alpha, \beta, \gamma$-toxins; leukocidin & Staphylococcal pyogenic \\
& Enterotoxin & infections \\
& Erythrogenic toxin & Staphylococcal food poisoning \\
& & Staphylococcal scarlet fever \\
Streptococcus pyogenes & Streptolysins O and S & Streptococcal pyogenic \\
& Erythrogenic toxin & infections \\
Shigella dysenteriae & Neurotoxin & Streptococcal scarlet fever \\
Salmonella Typhi & Endotoxins & Bacillary dysentery \\
Vibrio cholerae & Endotoxins & Gastroenteritis; enteric fever \\
\hline
\end{tabular}

Table 10.4. Factors influencing virulence.

\begin{tabular}{|c|c|}
\hline Factor & Action \\
\hline Hyaluronidase (spreading factor) & $\begin{array}{l}\text { Facilitates diffusion of pathogens and toxin materials } \\
\text { through host tissues. Increases permeability of tissue } \\
\text { spaces. }\end{array}$ \\
\hline Coagulase & Causes resistance to phagocytosis. \\
\hline Hemolysins & Destroy red blood cells and other tissue cells. \\
\hline Lecithinase "alpha toxin" & Causes lysis of red blood cells and other tissue cells. \\
\hline Collagenase & Dissolves collagen. \\
\hline Leucocidin & Kills leucocytes. \\
\hline $\begin{array}{l}\text { Streptokinase (streptococcal } \\
\text { fibrinolysin), streptodornase }\end{array}$ & Dissolves human fibrin. \\
\hline Exotoxins & $\begin{array}{l}\text { Cause degeneration of host cells. Block essential } \\
\text { metabolites, i.e., enzymes. Render substrates } \\
\text { unsusceptible to bacterial enzymatic digestion. Prevent } \\
\text { enzyme synthesis by the cell. }\end{array}$ \\
\hline Endotoxins & $\begin{array}{l}\text { Liberated on cell lysis, less potent than exotoxins. Causes } \\
\text { diarrhea, shock, and circulatory disturbances. }\end{array}$ \\
\hline Capsules & Enable some bacterial to resist phagocytosis. \\
\hline
\end{tabular}

products can play a significant role in determining the outcome of an infection. Table 10.4 lists some of these microbial factors that influences virulence).

\subsection{Factors Influencing Airborne Contagion}

Many factors influence the inhalation, deposition, and retention of inhaled materials whether microorganisms or chemicals is in the respiratory tract. These factors may also influence the response of the lungs and other organs as well as dose- 
response relationships to various inhalation exposures of chemicals, microorganisms, or their products.

The number of microbes required to cause a disease in a given host is called the infective dose. The infective dose varies not only with the strain of the microorganism, but also with the host. A number of factors play a role in making the host susceptible to an infectious organism. Exposure to cold, heat, certain stress like exercise, poor nutrition, age, secondary infections, and the interaction of the infectious agent with numerous noxious substances found in the host's environment (pollution) can modify and complicate the etiology and pathogenesis of the disease (Gardner, 1988; Coffin and Gardner, 1972; Graham et al., 1987).

In general, the number of organisms required to cause disease is usually proportional to their virulence. When an extremely virulent organism enters the body through its natural portal of entry, very few organisms are required to establish an infection. Less virulent strains may require considerably greater numbers to establish infection. Some microorganisms have a special affinity for the respiratory tract and establishes infection in the bronchi and lungs; tuberculosis and diphtheria usually enter by this portal. To produce lobar pneumonia, the pneumococcus, regardless of its virulence, must enter the lungs via the respiratory passages. The infectivity dose also varies with the host species.

\subsubsection{Methods of Study}

There are three general approaches for studying the pathogenesis of infectious disease: these include epidemiological, human clinical, and animal studies. The optimal database for assessing health risk has information from all three approaches because this minimizes the inherent limitations of each. Epidemiological studies are conducted to determine the correlation between exposure and disease. Unfortunately, epidemiological studies alone have great difficulties in proving causative relationships because of the many confounding variables. Such studies can show an association between exposure and effects and identify qualitatively the potential for human risk.

Although controlled human clinical studies offer the best opportunity to directly relate the cause of an infectious agent to human effects, they too have deficiencies. Because the safety of the volunteer is of paramount importance, the test substance can have no long-term residual effects, restricting such studies to exposure to organism with limited pathogenicity or completely nonpathogenicity, and complete recovery must be ensured. Only rather typical medical diagnostic procedures can be performed to follow the course of the disease.

The strengths of well-designed animal studies are that they can provide complete evaluation of the infectious aerosol. The researcher has the choice of a wide range of concentrations, exposure regimens, biological agents, biological parameters, and test species. Such studies are most useful in studying the pathogenesis of the disease. Because many physiological mechanisms are common to 
animals and humans, scientists hypothesize that if an agent is infective in several animal species, it is likely to cause a similar effect in humans. However, care must be taken in attempting to quantitatively extrapolate the effective airborne infectious concentration in animals to the human and that certain defense mechanisms may differ in various species.

\subsubsection{Experimental Infections of the Lung}

Laboratory-induced pulmonary infections have been useful in understanding the (1) pathogenicity of microorganisms, (2) environmental factors that alter susceptibility to respiratory disease, and (3) mechanisms of host resistance to infection. By using the appropriate animal model, one can measure subtle defects of the total pulmonary defense system by testing the lungs ability to efficiently defend itself against invading, potentially pathogenic organisms. The three experimental techniques that have been most widely used in the laboratory to expose a test animal to an airborne infectious organism includes (1) aerosolization, (2) intratracheal instillation, and (3) intranasal inoculation.

Aerosolization of the microorganism most closely mimics or simulates a natural exposure. This method provides the most uniform exposure of the animal and is applicable to a wide variety of pathogenic organisms. To conduct such exposures requires expensive equipment and a team of scientists with expertise in aerosol sciences, engineering, and biology as well as specialized containment to ensure the health and safety of the investigators (Phalen, 1984; Gardner, 1988).

Organisms may also be instilled intratracheally in an anaesthetized animal. Although these studies are less costly, one cannot guarantee a uniform distribution throughout the lung as with inhalation exposure (Hatch et al., 1981; Phalen, 1984). Also, the need to anesthetize the test animal results in an unnatural condition of exposure.

Intranasal inoculation of microorganisms has been used for years. With this method, one must depend on the aspiration of the inoculum to spread the infectious organism from the upper respiratory tract to the conducting airways and deep lung. Both this technique and intratracheal instillation can result in considerably more animal-to-animal variation than with the aerosol challenge.

Ideally, whichever experimental model is chosen, certain criteria needs to be considered. Any experimental model should (1) yield reproducible data; (2) permit correlation among species of test animals; (3) ensure the sensitivity of the test animal to the microorganism, and (4) facilitate the ability for direct comparison of data with that from mechanistic studies. The test organism must be able to (1) multiply within the infected susceptible host tissue, (2) be quantifiable at the administered dose, (3) trace and follow during the infectious and recovery phase; (4) not greatly influence mortality rate with small variations in dose or virulence and (5) withstand the vigors of aerosolization if the route of administration is by inhalation. 
Such in vivo exposure studies can be used to provide vital information on survival statistics, growth, replication, and fate of the infectious organism in the host tissue and mechanistic studies using sensitive biochemical and immunological measurements

\subsection{Summary}

The health aspects of bioaerosols have been reviewed in terms of sources, particle size, and dose-response. Airborne contagion and factors influencing this are also discussed. The anatomical and physiological factors in respiratory deposition and dosimetry of infectious organisms are described as are the processes of infectious methods of study and experimental infections of the lung. The advent of biotechnology and genetic engineering will expand the horizons of bioaerosols. Hopefully, these processes will be employed for the benefit of mankind.

\section{References}

Al-Dagal, M., and D. Y. Fung. 1990. Aeromicrobiology-A review. Crit. Rev. Food Sci. Nutr. 29:333-340.

Aldovini, A., and R. A. Young. 1992. The new vaccines. Technol. Rev. 95:24-31.

Bates, D. V., D. L. Dungworth, P. N. Lee, R. O. McClellan, and F. J. C. Roe. 1989. Assessment of inhalation hazards. Springer-Verlag, New York.

Baum, R. M. 1987a. Biotech industry moving pharmaceutical products to market. Chemical and Engineering News 65(29):11-32.

Baum, R. M. 1987b. Agricultural biotechnology advances toward commercialization. Chemical and Engineering News 65(32):9-14.

Brachman, P. S. 1980. Inhalation anthrax. Pp. 83-93. In R. B. Kundsin, (ed.), Airborne contagion. Annals of New York Academy of Sciences, New York. 353.

Breiman, R. F., W. Cozen, B. S. Fields, T. D. Mastro, S. J. Carr, J. S. Spika, and L. Mascola. 1990. Role of air sampling in investigation of an outbreak of Legionnaires' disease associated with exposure to aerosols from an evaporative condenser. J. Infect. Dis. 161:1257-1261.

Burge, H. A. 1987. Toxigenic potential of indoor microbial aerosols. In S. S. Sandhu, D. M. Demarini, M. J. Mass, M. M. Moore, and J. L. Mumford, (eds.), Short-term bioassays in the analysis of complex environmental mixtures. Plenum, New York.

Burge, H. 1990. Bioaerosols: Prevalence and health effects in the indoor environment. J. Allergy Clin. Immunol. 86:687-701.

Coffin, D. L., and D. E. Gardner. 1972. Interaction of biological agents and chemical air pollutants. Ann. Occup. Hyg. 15:219-235.

Conant, N. F. 1976. Fungous diseases involving internal organs, Pp. 1056-1057. In W. K. Joklik and H. P. Willett (eds.), Zinsser microbiology. Appleton-Century-Crofts, New York. 
Crystal, R. G., J. B. West, P. J. Barnes, N. S. Cherniack, and E. R. Weibel (eds.). 1991. The lung: Scientific foundations. Raven Press, New York.

Donham, K. J. 1991. Association of environmental air contaminants with disease and productivity in swine. Amer. J. Vet. Res. 52:1723-1730.

Druett, H. A., D. W. Henderson, L. Packman, and S. Peacock. 1953. Studies on respiratory infection. 1 . The influence of particle size on respiratory infection with anthrax spores. J. Hyg. 51:359.

Duguid, J. P. 1945. The number and sites of origin of droplets expelled during expiratory activities. Edinb. Med. J. 52:385-401.

Edwards, J. H., A. J. Griffiths, and J. Mullins. 1976. Protozoa as sources of antigens in humidifier fever. Nature 264:438.

Fenstersheib, M. D., M. Miller, C. Diggins, S. Liska, L. Detwiler, S. B. Werner, D. Lindquist, W. L. Thacker, and R. F. Benson. 1990. Outbreak of Pontiac fever due to Legionella Anisa. Lancet 336:35-37.

Fraser, D. W. 1980. Legionellosis: Evidence of airborne transmission. Pp. 61-66. In R.B. Kundsin, (ed.), Airborne contagion. Annals of New York Academy of Sciences, New York. 353.

Gallis, H. A. 1976. Microbial ecology and normal flora of the human body. Pp. 404 412. In W. K. Joklik and H. P. Willett (eds.), Zinsser microbiology. Appleton-CenturyCrofts, New York.

Gardner, D. E., J. D. Crapo, and E. J. Massaro. (eds.) 1988. Toxicology of the lung. Target Organ Toxicology series. Raven Press, New York.

Gardner, D. E. 1988. The use of experimental infections to monitor improvements in pulmonary defense. J. Appl. Toxicol. 6:385-388.

Goodlow, R. J., and F.A. Leonard. 1961. Viability and infectivity of microorganisms in experimental airborne infection. Bacteriol. Rev. 25:182.

Gershon, D. 1992. Genetically engineered foods get green light. Nature 357:352.

Glanz, J. 1992. Herman: The pharmaceutical industry's next star? R\&D Mag. 34:3642.

Graham, J. A., D. E. Gardner, E. J. Blommer, D. E. House, M. G. Menache, and F. J. Miller. 1987. Influence of exposure patterns of nitrogen dioxide and modifications by ozone on susceptibility to bacterial disease in mice. J. Toxicol. Environ. Health 21:113125.

Gwaltney, J. M., Jr. 1980. Epidemiology of the common cold. Pp. 54-60. In R. B. Kundsin, (ed.), Airborne contagion. Annals of New York Academy of Sciences, New York.

Hatch, G. E., R. Slade, E. Boykin, F. G. Miller, and D. E. Gardner. 1981. Correlation of effects of inhaled versus intratracheally injected metals on susceptibility to infection. Amer. Rev. Respir. Dis. 124:167-173.

Hatch, T. F. 1961. Distribution and deposition of inhaled particles in respiratory tract. Bacteriol. Rev. 25:237-240. 
Hatch, T. F., and P. Gross. 1964. Pulmonary deposition and retention of inhaled aerosols. Academic Press, New York. Pp. 137-145.

Herman, L. G. 1980. Aspergillus in patient care areas. Pp. 140-146. In R. B. Kundsin, (ed.), Airborne contagion. Annals of New York Academy of Sciences, New York.

Jennison, M.W. 1942. Atomizing of mouth and nose Secretions into the air as revealed by high-speed photography. Pp. 106-128. In F. R. Moulton, (ed.), Aerobiology. American Association for the Advancement of the Sciences, Washington, D.C.

Joklik, W. K. 1976. Poxviruses. Pp. 937-944. In W. K. Joklik and H. P. Willett (ed.), Zinsser microbiology. Appleton-Century-Crofts, New York.

Kaminski. E., S. Stawicki, and E. Wasowicz. 1974. Volatile flavor compounds produced by molds of aspergillus, penicillium, and fungi Imperfecti. Appl. Microbiol. 27:1001.

Kaufmann, A. F., M. D. Fox, J.M. Boyce, D. C. Anderson, M. E. Potter, W. J. Martone, and C. M. Patton. 1980. Airborne spread of brucellosis. Pp. 105-114. In R. B. Kundsin, (ed.), Airborne contagion. Annals of New York Academy of Science, New York.

Ketchum, P. M. 1988. Microbiology: Concepts and applications. John Wiley \& Sons, New York.

Kundsin, R. B. 1980. Opening remarks. Pp. 1-2. In R. B. Kundsin, (ed.), Airborne contagion. Annals of New York Academy of Sciences, New York.

Lange, D. J. 1976. Herpesviruses. Pp. 947-949. In W. K. Joklik and H. P. Willett (eds.), Zinsser microbiology. Appleton-Century-Crofts, New York.

Lee, J. V., and A. A. West. 1991. Survival and growth of Legionella species in the environment. J. Appl. Bacteriol. (Symp. Suppl.) 70:121S-129S.

Mallison, G. F. 1980. Legionellosis: Environmental aspects. Pp. 67-70. In R. B. Kundsin, (ed.), Airborne contagion. Annals of New York Academy of Science, New York.

Mannis, M. J., R. Tamaru, A. M. Roth, M. Burns, and C. Thirkill. 1986. Acanthamoeba Sclerokeratitis. Arch. Ophthalmol. 104:1313.

McClellan, R. O. and F. F. Henderson. (eds.). 1989. Concepts in inhalation toxicology. Hemisphere Publishing Co., New York.

Miller, F. J., and D. B. Menzel. (eds.). 1989. Extrapolation modeling of inhaled toxicants. Hemisphere Publishing Co., New York.

National Research Council. 1991. Human exposure assessment for airborne pollutants: Advances and opportunities. National Academy Press, Washington, D.C.

O’Mahony, M. C., R. E. Stanwell-Smith, H. E. Tillett, D. Harper, G. P. Hutchison, I. D. Farrell, D. N. Hutchinson, J. V. Lee, P. J. Dennis, H. V. Duggal, J. A. Scully, and C. Denne. 1990. The Stafford outbreak of Legionnaires' disease. Epidemiol. Infect. 104:361-380.

Parker, R. F., J. K. Davis, and G. H. Cassell. 1989. Short term exposure to nitrogen dioxide enhances susceptibility to respiratory mycoplasmosis and decreases in intrapulmonary killing of mycoplasma pulmonia. Amer. Rev. Resp. Dis. 140:502-512.

Phalen, R. F. 1984. Inhalation studies: Foundation and techniques. CRC Press, Boca Raton, FL. 
Poupard, J. A., L. A. Miller, and L. Granshaw. 1989. The use of smallpox as a biological weapon in the French and Indian War of 1763. ASM News 55:122-124.

Powledge, T. M. 1992. Gene pharming. Technol. Rev. 95:61-66.

Salem, H., and D. M. Aviado. 1970. Physiology of the cough reflex. Pp. 233-270. In International encyclopedia of pharmacology and therapeutics. Section 27, Vol.1. Antitussive agents. H. Salem and D.M. Aviado (eds.).

Salem, H. 1987. Principles of inhalation toxicology. Pp. 1-33. In H. Salem (ed.), Inhalation toxicology. Marcel Dekker, Inc. New York.

Salem, H., G. L. Kennedy, J. B. Morris, M. V. Roloff, C. E. Ulrich, R. Valentine, and R.K. Wolff. 1992. Recommendations for the conduct of acute inhalation limit tests. Fund. Appl. Toxicol. 18:321-327.

Spendlove, J. C., and K. F. Fannin. 1983. Source, significance, and control of indoor microbial aerosols: Human health aspects. Public Health Rep. 98:229.

Sprengler, J. D., and K. Sexton. Indoor air pollution: A public health perspective. Science 221:9-17.

Titball, R. W., P. C. B. Turnbull, and R. A. Hutson. 1991. The monitoring and detection of Bacillus-anthracis in the environment. J. Appl. Bacteriol. (Symp. Suppl. 70:9S$18 \mathrm{~S}$.

Wells, W. F. 1934. On air-borne infection: II. Droplets and droplet nuclei. Amer. Hyg. 20:611.

Wells, W. F. 1955. Air-borne contagion and air hygiene. Harvard University Press, Cambridge, MA.

Wells, W. F., H. L. Ratcliffe, and C. Crumb. 1948. On the mechanism of dropletnucleus infection. II. Quantitative experimental air-borne turberculosis in rabbits. Amer. J. Hyg. 47:11.

Yamamoto, K. R. 1989. Retargeting research on biological weapons. Technol. Rev. 92:23-24. 